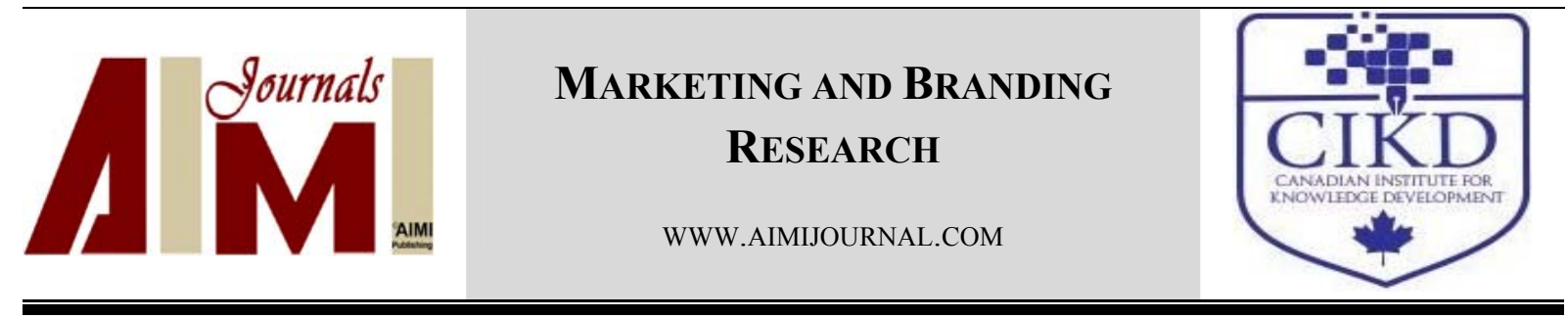

\title{
Energy Dependence of the Solar Business of the European Union and Bulgaria
}

\author{
Noncho Dimitrov \\ Department “National and Regional Security”, Faculty “Economics of Infrastructure”, University of National \\ and World Economy
}

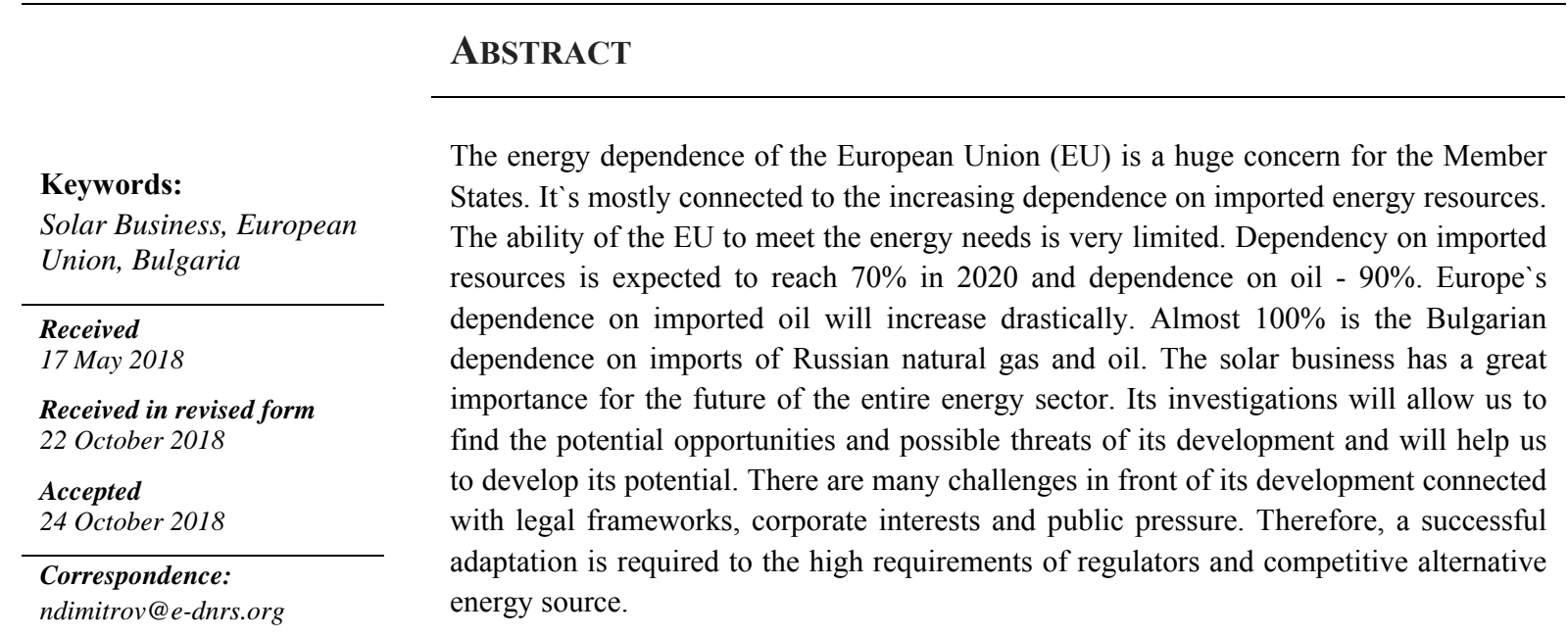

C)AIMI Journals

\section{The Importance of the Renewable Energy Resources}

The solar business is of a huge importance or the future of the world's energy. One of the main goals of EU is promoting the solar business and the renewable energy sources (RES). According to EU's directives, the share of those type of sources in total EU energy consumption is going to double it and to reach $20 \%$ of total energy consumption. Measures have been taken to promote RES and to increase energy efficiency (Tonchev, 2008). Also, 
there are different programs supporting projects for the development of the solar business and expanding cooperation between the EU and the developing countries in the field of RES.

In Bulgaria, the share of those type of energy sources in total consumption in 2009 phenomena was $9 \%$, due to the work of hydroelectric power plants (HEPP). In 2012, it was almost $13 \%$, and after the boom of photovoltaic power plants in the period 2012-2014, this share amounts to $16 \%$, which is our commitment to achieving a relative share of the consumption of energy from RES in the total energy consumption by 2020 (Manov, 2002).

Part of the prospects of the solar business is linked to the reduction of greenhouse gas emissions. At the United Nations Conference in Kyoto in December 1997, the EU pledged to reduce its $\mathrm{CO}_{2}$ emissions by $8 \%$ from 1990 levels. One of the world's largest emissions trading schemes has been set up. The Republic of Bulgaria ratified the United Nations Framework Convention on Climate Change and the Kyoto Protocol in March 1997 and is currently meeting its requirements. As a member of the EU, our country also joined the first Emissions Trading Scheme (ETS) and will continue to participate in it during the second period. Bulgaria is actively involved in the Joint Implementation mechanism of the Kyoto Protocol and is preparing for the introduction of the EU ETS from 2007.

Considering that sunshine in our country is significantly higher than the average European indicators, investments in solar photovoltaic parks are a profitable investment in technology, but they are still expensive industry. The resource (sunshine) is practically unlimited and completely free. The production market (the purchase of electricity) is still guaranteed not only by the state but also by the European directives. All transmission and distribution companies must prioritize photovoltaic power plants as long as they agree to buy out. European energy policy (SEC 2007) has a number of measures aimed at achieving an integrated energy market, security of energy supply and the sustainable development of the energy sector.

By 2020, in Bulgaria, the amount of electricity production from RES should be doubled in order to meet the needs and replace with half of the existing plants that will have to be decommissioned. RES is a possible choice for the development of fuels that do not emit carbon oxides. On one hand, they reduce dependency on imported resources outside the EU and, on the other hand, they contribute to environmental protection. Germany is the most obvious example of a purposeful policy of stimulating RES. The installed capacity in wind farms in the country is as much as the installed capacity in Bulgaria. However, their production is about $7 \%$ of the total production. It's important to mention that for every installed megawatt in a green power plant, a reserve of one megawatt of coal should be built. For example, Denmark, which produces $20 \%$ of its energy from RES, is the largest emitter of carbon oxides per capita to ensure a continuous supply of energy.

The most efficient solutions are in the field of consumption. The daily priorities are in the rational use of electricity, in the creation of regulatory and price conditions for a complete transformation of the culture of consumption and education of our responsibilities as consumers. But the focus is not only on end-users of electricity. Specific measures also require the transport sector, with the target of $20 \%$ of the fuels in the transport sector being replaced by biofuels by 2020 . For the new Member States, the issue of energy intensity of 
GDP is part of the more important issue of their competitiveness in the common European market.

Another sector subject to specific mandatory energy saving requirements is construction. All countries in the Union have obligations to introduce standards for energy auditing, sanitation and certification of buildings. Reasonable use of energy also means providing options for selecting the type of energy according to specific needs - wide access to natural gas, modernization and development of centralized heating systems, development of small, decentralized sources to cover domestic energy needs.

A comprehensive legal, regulatory and pricing environment for modernization and investment activity in the field of rational use of energy has been created. The concrete tools to support investment in energy efficiency are also strategically important.

\section{Energy Dependence of the Solar Business}

The EU's energy dependence on imports has intensified over the past two decades and is most pronounced in the case of gas supply. The expectations are that by 2035, $80 \%$ of gas consumption in Europe will come from imports. These imports are tied to long-term supply contracts, with the largest share being Russia's, which in turn successfully uses the price of gas supplies for its foreign policy needs. This strategy places Bulgaria among the most gasdependent countries. Our country is dependent on Russian imports of natural gas and oil almost to $100 \%$.

After 2007, the tensions and the risks for Bulgaria from the inconsistencies between the country's EU membership, the declared and the real follow-up of the European energy strategy on the one hand, and its dependence on project engagement with Russia on the other, were intensified. This conflict has highlighted the worst management practices in the Bulgarian energy sector, linked to substantial financial losses to the state and its legislative uncertainty.

Here we can also add the lack of regulatory independence and supervisory capacity in the sector. Bulgaria is the most vulnerable country in terms of energy security. The country's position has deteriorated steadily over the past decade, but the decline has been particularly sensitive over the past five years, as rising energy prices have seriously undermined the ability of households in the poorest EU Member States to meet their energy needs.

A major risk to the country's energy security is the high level of energy poverty. Over onethird of Bulgarian households cannot afford to adequately heat their homes and more than $60 \%$ still use mainly coal and wood for heating. Economic stagnation has led to a further impoverishment of the most vulnerable groups after 2009, which has made it politically impossible to raise electricity prices and, hence, ensure return on investment in the sector. The extremely high proportion of the population, dependent on social and other state support, implies a very serious risk of burdening public finances as a result of the country's energy dependence. With the retention of electricity prices, this burden is shifted from the state budget to the balance sheets of state-owned enterprises, but ultimately remains the burden of taxpayers.

Another risk is the high energy intensity of the economy, both in the business sector and in the households. It is complemented by very high losses in the transformation, transmission, 
reallocation and consumption of energy, which for Bulgaria reach $50 \%$ of the primary energy compared to the average of $30 \%$ for Europe (National Statistical Institute, 2008). Although energy efficiency has steadily increased over the last decade, the country's economy remains more energy intensive than the EU average. This energy intensity, coupled with the high dependence of the Bulgarian economy on imports of non-renewable energy sources (NRES), leads to a very low elasticity of the cost of energy raw materials and significant fluctuations in the aggregate energy costs. Bulgaria's average annual import costs for solar power and NRES vary between $8 \%$ and $13 \%$ of GDP, putting the economy under severe stress with rising prices on international markets.

With the exception of local extraction of low-carbon coal, Bulgaria is fully dependent on imports of NRES. This dependence on gas supply is particularly acute, as the market is not liberalized, but in practice, it only relies on one supplier for a single pipeline. Because of this, the country pays one of the highest gas supply prices in Europe, and just under 1\% of households use gas for heating. Lack of alternative supplies closes the country trapped by energy dependence, as the population replaces expensive gas with heating electricity, forcing the government to artificially hold electricity prices, freezing the technological development of the sector (Pavlov, 1998). The crisis in Ukraine has become an additional risk factor for the supply of natural gas to Europe and the realization of gas energy projects in Bulgaria.

In general, the focus of state energy policy over the past decade is on major infrastructure projects that require substantial public investment and / or guarantees, do not diversify energy sources and have no potential for price and cost reduction (Hristov, 2007). The experience with similar strategies in the past shows that the end results are serious price pressures and widespread public outrage. Maintaining electricity prices, another major state energy policy over the past five years, has led to the accumulation of debt in state-owned energy companies and blocking the investment process with long-term negative consequences for the energy sector. All this has led to the market liberalization of the electricity market, which further closes the system in the deadlock.

There is also a specific risk factor in Bulgaria - the quality of management in the energy sector. Most clearly expressed in the management of state energy companies and in the way of structuring and managing public procurement, includes the mega energy projects in which the state is involved. The financial health of the companies in the Bulgarian Energy Holding is seriously undermined. Part of the problem comes from the administrative control of prices and the frequent and unclear changes in them by the regulator, which led to the accumulation of debts in the two key state-owned companies - NEK and Bulgargaz, respectively in the electricity and gas sectors. Both enterprises are in extremely poor financial condition, making them unprepared for participation in the liberalized market.

Managerial deficits in the energy sector are not limited to financial and regulatory conditions, but also include human resource management in state-owned companies and the regulator. Frequent shifts in state-owned management teams imply their strong political loyalty and lack of independence in their decisions on the operation of companies. This vicious practice facilitates the takeover of state-owned enterprises from private interests, which ultimately leads to their draining and indebtedness.

From the above, for the solar business, it is important to draw the following conclusions: 
- the priority of energy security should not only be the security of supply, but also all opportunities for the state to increase its energy independence;

- RES allow us to understand the energy strategy in Bulgaria for assessing the perspectives, providing the necessary information, creating financial stability, modernizing the existing practices;

- in the implementation of the EU's Financial Program for Bulgaria until 2013, the Government has adopted some European Commission proposals on RES, which guarantees the purchase of the electricity produced from these sources at preferential prices. This, in turn, guarantees the return on investment in this area.

The EU has underlined its commitment to international co-operation and combating the effects of greenhouse gas emissions. However, the 1992 proposal on the introduction of a $\mathrm{CO} 2$ and energy tax is still not implemented due to strong opposition from several countries and lack of support from major competitors (US and Japan) on international markets. However, the EU is working hard to reduce emissions.

The European Council called for an Energy Policy for Europe (EPE). It should be based on shared perspectives on long-term demand and supply, an objective, transparent assessment of the advantages and disadvantages of all energy sources and contribute in a balanced way to its three main objectives: a) enhancing the security of supply; b) ensuring the competitiveness of European economies and the availability of affordable energy; c) supporting the sustainability of the environment, continuing the development of renewable energy sources, and implementing the Biomass Action Plan.

The formation of the internal market in the energy sector requires the elimination of many obstacles and trade barriers, approximation of tax and pricing policies, measures on standards and standards, and environmental and safety regulations. To this end, the EU is creating a number of directives on electricity and gas transmission, which aims to open markets to competition.

The increasing dependence of some Western countries on energy imports and their increased energy vulnerability, which creates a favorable environment for future inter-state conflict of resources, is of paramount importance. Europe is poor on its own energy resources. Production costs for extraction of oil, gas and coal are extremely high. There is significant RES potential but it is not enough to meet industrial demand. The main challenge facing the Community remains the increasing dependence on energy resources. The EU has limited opportunities for response. The dependence on imported resources will reach $70 \%$ in 2020 and dependence on oil - 90\%. The main importer of natural gas remains Russia, importer of oil - the Middle East. In addition to this dependence, which requires flexible geopolitical solutions, the environmental consequences of the use of organic fuels are compounded.

Europe's dependence on oil imports will increase drastically in the medium term, as output in the North Sea is expected to progressively decrease and be completely discontinued around 2030. Gulf oil imports by 2020 are expected to exceed 50\% for the EU. Natural gas consumption in European countries has seen rapid growth since the 1990s due to the displacement of oil as a heating fuel. In the EU's energy mix, the share of natural gas is expected to rise from the current $22 \%$ to $29 \%$ by 2030 . The EU imports $40 \%$ of its gas 
consumption. The most significant part of the imports is from Russia (42\%) and from Algeria $(30 \%)$. For the foreseeable future, these two countries will remain the largest external suppliers of the European gas market.

The EU is responsible for creating around $20 \%$ of the world's $\mathrm{CO} 2$ emissions. Notwithstanding all measures and commitments, in 2010-2020, these emissions will be $20 \%$ above and not $8 \%$ below the 1990 level, as required by the Kyoto Protocol. In addition to limiting greenhouse gas emissions, significant investment resources must also be provided to meet the limitations of other anthropogenic gases (Tonchev, 2008).

The contribution of RES depends on the political will to be supported and on achieving attractive economic conditions in the production of energy from them. The liberalization of energy markets will certainly improve the efficiency of the system, leading to market price regulation. This, however, will stimulate consumers towards higher consumption of resources. Low prices also mean a delay in investment decisions and a maximum delay in the construction of new capacities. On this basis, each European economy chooses a different strategy to meet the energy challenges.

\section{Conclusions}

RES is a possible choice for the development of fuels that do not emit carbon oxides. They meet the requirements in the EU countries - on the one hand, they reduce dependence on imported resources outside the Eurozone and on the other hand they contribute to the protection of the environment.

The modern world faces the challenge of energy and the environment, a challenge that is clear for Europe and shared by all Member States. There is a tremendous need to provide competitive and clean energy in the conditions of climate change, increasing global demand for energy and uncertainty about future deliveries. If a Member State fails to address the challenge, it will also affect the other Member States. If problems arise outside the EU, they can affect the whole of the EU. That is why Europe needs a sound energy policy amid a depletion of energy and a growing dependency on raw materials imports. It is likely that many of the oil and gas producing countries will face a limited time because of their limited reserves with the inability to increase their production capacity to the planned level and the supply commitments made. Soon the first effects of resource depletion will be felt, the more likely the interruptions in the supply of energy products will endanger the energy and national security of our country. The future of energy is in the solar business, and the future of the solar business is predictable.

\section{References}

Hristov, S. (2007). Strategic Management in the Collective Security and Defense System (1st ed.). Sofia, Bulgaria: University Publishing House.

Manov, A. (2002). Multidimensional statistical methods with SPSS (1st ed.). Sofia, Bulgaria: University Publishing House.

National Statistical Institute. (2008). Energy balance - 2007. Sofia, Bulgaria: Statistical Yearbook.

Pavlov, P. (1998). Expert-analytical methods in strategic management (1st ed.). Sofia, Bulgaria: Prizma.

Tonchev, G. (2008). New energy (1st ed.). Sofia, Bulgaria: Ecowatt Technologies Publishing House. 